\title{
A Comparative Study of Immunoglobulin (E) Levels in the Nasal Mucosa and Blood in Chronic Rhinosinusitis Patients With and Without Nasal Polyps
}

\author{
MOHAMED S.M. KASSEM, M.Sc.*; EMAD M.K. SHEHATA, M.D.**; HASSAN M. HEGAZY, M.D.** and \\ YASSER I. AGLAN, M.D.**
}

The Departments of Otorhinolaryngology* and Otolaryngology**, Faculty of Medicine, Tanta University

\begin{abstract}
Background: Rhinosinusitis is a significant health problem, which results in a large financial burden on the society. Chronic rhinosinusitis is a multi-factorial disease. These factors are mucociliairy impairment, (bacterial) infection, allergy, asthma, genetic factors and environmental factors. Critical analysis of the papers linking atopy as a risk factor to rhinosinusitis (chronic or acute). Immunoglobulin E (IgE) levels increase when patient exposed to common antigens (e.g., house dust, animal dander and pollen) with increased production of allergen-specific IgE.
\end{abstract}

Aim of Study: The aim of this work is to compare the level of IgE in the nasal mucosa and blood in chronic rhinosinusitis patients with and without nasal polyps.

Patients and Methods: 60 patients, presented with Chronic rhinosinusitis with and without nasal polyps were enrolled in the study. Patients were divided into two groups: (Group I) Chronic rhinosinusitis patients with nasal polyps and (group II) Chronic rhinosinusitis patients without nasal polyps. Levels of total and local IgE were measured in two groups.

Results: Group I show that local IgE was high than normal but total IgE was within normal range. Group II shows that local and total IgE were within normal range.

Conclusions: This study suggests a higher prevalence of allergy in Chronic Rhinosinusitis patients with Nasal Polyps (CRSwNP) than Chronic Rhinosinusitis patients without Nasal Polyps (CRSsNP).

Key Words: Local IgE - Total IgE - Chronic rhinosinusitis patients with nasal polyps (CRSwNP) - Chronic rhinosinusitis patients without nasal polyps (CRSs$N P)$.

\section{Introduction}

RHINOSINUSITIS is a significant health problem, which results in a large financial burden on the society [1]. The cost of physician visits resulting

Correspondence to: Dr. Mohamed S.M. Kassem,

The Department of Otorhinolaryngology, Faculty of Medicine, Tanta University in a primary diagnosis of sinusitis was 3.39 billion dollars, which does not reflect the complete cost of radiographic studies and medication [2] .

Chronic Rhinosinusitis (CRS) can be divided into: Chronic Rhinosinusitis with Nasal Polyps (CRSwNP) and Chronic Rhinosinusitis without Nasal Polyps (CRSsNP) [3].

Chronic rhinosinusitis is a multi-factorial disease. These factors are mucociliairy impairment, (bacterial) infection, allergy, asthma, genetic factors and environmental factors. Morphological/ anatomical variations in the nasal cavity or paranasal sinuses as concha bullosa and nasal septal deviation play an important role as a predisposing factor [3]

Critical analysis of the papers linking atopy as a risk factor to infective rhinosinusitis (chronic or acute) reveal that whilst many of the studies suggest a higher prevalence of allergy in patients presenting with symptoms consistent with sinusitis than would be expected in the general population. A number of studies report that markers of atopy are more prevalent in populations with CRS [4].

Atopy is a clinical syndrome involving type I hypersensitivity (allergy) with a hereditary predisposition. Immunoglobulin E (IgE) levels increase when patient exposed to common antigens (e.g., house dust, animal dander and pollen) with increased production of allergen-specific IgE [5] .

\section{Patients and Methods}

This study was conducted in Otorhinolaryngology Head and Neck Surgery Department, Tanta University Hospital from first of April 2017 till the first of April 2018. The study included 60 patients. Patients were divided into two main groups 
Group A: Chronic rhinosinusitis patients with nasal polyps. Group B: Chronic rhinosinusitis patients without nasal polyps. The 60 patients were chosen from patients visiting the outpatient clinic of Otorhinolaryngology Head and Neck Surgery Department, Tanta University Hospital.

Every patient had a number from 1-30 that chosen randomly from already prepared cards but included to his group (A or B).

\section{Inclusion criteria:}

Chronic rhinosinusitis patients with and without nasal polyp reach maximum medical treatment (at least one year) in form of (systemic anti-histaminic, systemic antibiotic, local vasoconstrictor and local nasal corticosteroid spray).

\section{Exclusion criteria:}

Parasitic diseases e.g. ascariasis and schistosomiasis, myloma, lymphoma, chemotherapy or radiotherapy for any tumor and specific immunotherapy during the 3 years before study entry or during the study. Patients who refuse participation in this study.

Diagnostic nasal endoscopy was done for all patients at the time of initial evaluation in the outpatient clinic and the findings were recorded. Diagnostic nasal endoscopy was done while the patient was seated in the upright position and examination was performed with the 0 -degree wide angle $4 \mathrm{~mm}$ telescope.

Detect IgE levels in the nasal mucosa by nasal swab and blood sample total IgE measurement.

\section{Blood testing:}

All patients had a blood test to measure the concentration of total IgE. Blood was collected by performing a standard venipuncture and allowed to clot for 15-30 minutes. After that the blood was centrifuged for 15 minutes at $1500 \mathrm{~g}$ at $4^{\circ} \mathrm{C}$. Serum was stored in aliquots at $-20^{\circ} \mathrm{C}$ until further analysis with (Cobas-C \& Cobas-E (Roche) 26 system.

\section{Sampling of nasal secretions for local IgE:}

Nasal swab was inserted on the floor of the nasal cavity between the septum and inferior turbinate under direct visualization using a surgical headlight, a speculum and then placed back in its respective tube.

\section{Results}

Regarding the demographic data as age and sex, Group I: The mean value for age was 41.7 ranging from 27 to 55 with standard deviation 8.4. They were 13 males (43.3\%) and 17 females $(56.7 \%)$. Group II: The mean value for age was 41.5 ranging from 28 to 52 with standard deviation 7.7. They were 11 males $(36.7 \%)$ and 19 females $(63.3 \%)$.

Group I: Chronic Rhinosinusitis patients with Nasal Polyps (CRSwNP) (30 patients) normal level of toal and local IgE was up to $100 \mathrm{U} / \mathrm{ml}$. The mean value for local IgE was 117.83 ranging from 46 to 178 with standard deviation 27.9 . The mean value for total $\mathrm{IgE}$ was 50.2 ranging from 12 to 108 with standard deviation 28.39 .

$p$-value was 0.0001 which means statistically significant. If $p$-value $\leq 0.05$ means statistically significant.

Group II: Chronic Rhinosinusitis patients without Nasal Polyps (CRSsNP) (30 patients) the mean value for local IgE was 47.33 ranging from 22 to 79 with standard deviation 17.9. The mean value for total IgE was 49 ranging from 18 to 89 with standard deviation 22.2. $p$-value was 0.161 which means statistically not significant.

Table (1): Comparison between the two groups as regard age.

\begin{tabular}{lll}
\hline Age & Group I & Group II \\
\hline Mean \pm SD & $41.7 \pm 8.4$ & $41.5 \pm 7.7$ \\
Range & $27-55$ & $28-52$ \\
$t$-test & $t$ & 0.112 \\
& $p$-value & 0.911 \\
\hline
\end{tabular}

Table (2): Comparison between the two groups as regard sex.

\begin{tabular}{cll}
\hline Sex & Group I & Group II \\
\hline Male: & & \\
No. & 13 & 11 \\
$\%$ & 43.3 & 36.7 \\
Female: & & \\
No. & 17 & 19 \\
$\%$ & 56.7 & 63.3 \\
Chi-square test & $\chi^{2}$ & 0.278 \\
& $p$-value & 0.598 \\
\hline
\end{tabular}

Table (3): Comparison of local IgE between two groups.

\begin{tabular}{lll}
\hline Local Ige & Group I & Group II \\
\hline Range & $46-178$ & $22-79$ \\
Mean \pm SD & $117.83 \pm 27.9$ & $47.33 \pm 17.9$ \\
Independent $t$-test & $t$ & 11.6 \\
& $p$-value & 0.0001 \\
\hline
\end{tabular}


Table (4): Comparison of total IgE between two groups.

\begin{tabular}{lll}
\hline Total Ige & Group I & Group II \\
\hline Range & $12-108$ & $18-89$ \\
Mean \pm SD & $50.2 \pm 28.39$ & $49 \pm 22.2$ \\
Independent $t$-test & $t$ & 0.177 \\
& $p$-value & 0.86 \\
\hline
\end{tabular}

Table (5): Comparison of IgE in group I chronic rhinosinusitis with nasal polyps (CRSwNP) IgE in group I.

\begin{tabular}{|c|c|c|}
\hline Patients No. & Local (U/ml) & Total $(\mathrm{U} / \mathrm{ml})$ \\
\hline 1 & 78 & 45 \\
\hline 2 & 74 & 12 \\
\hline 3 & 75 & 15 \\
\hline 4 & 110 & 18 \\
\hline 5 & 100 & 78 \\
\hline 6 & 102 & 108 \\
\hline 7 & 98 & 45 \\
\hline 8 & 110 & 43 \\
\hline 9 & 112 & 22 \\
\hline 10 & 115 & 28 \\
\hline 11 & 124 & 29 \\
\hline 12 & 130 & 23 \\
\hline 13 & 131 & 27 \\
\hline 14 & 151 & 75 \\
\hline 15 & 145 & 105 \\
\hline 16 & 170 & 74 \\
\hline 17 & 129 & 18 \\
\hline 18 & 145 & 19 \\
\hline 19 & 46 & 45 \\
\hline 20 & 178 & 39 \\
\hline 21 & 121 & 78 \\
\hline 22 & 119 & 107 \\
\hline 23 & 113 & 74 \\
\hline 24 & 114 & 72 \\
\hline 25 & 112 & 46 \\
\hline 26 & 114 & 43 \\
\hline 27 & 155 & 45 \\
\hline 28 & 132 & 78 \\
\hline 29 & 114 & 56 \\
\hline 30 & 118 & 39 \\
\hline Range & $46-178$ & 12-108 \\
\hline Mean \pm SD & $117.83 \pm 27.9$ & $50.2 \pm 28.39$ \\
\hline \multirow[t]{2}{*}{ Paired $t$-test } & $t$ & 10.2 \\
\hline & $p$-value & $0.0001 *$ \\
\hline
\end{tabular}

$(*)$ : Mean statistically significant ( $p$-value $\leq 0.05)$.

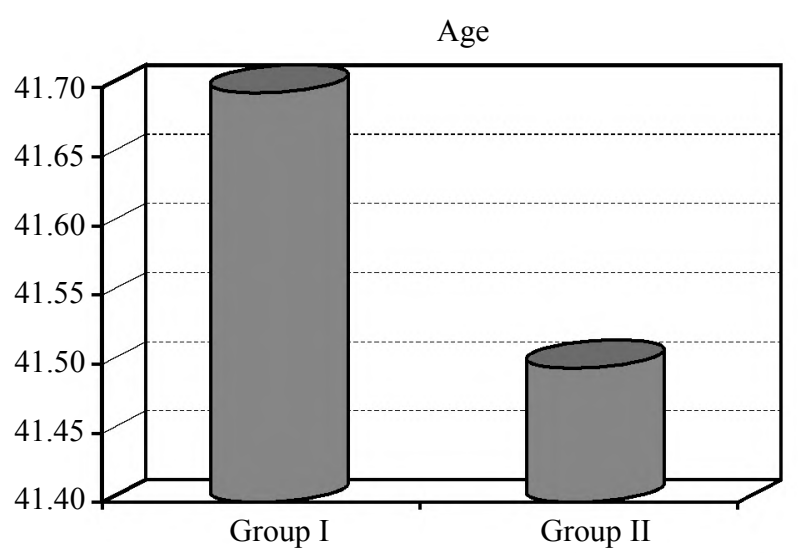

Fig. (1): Comparison between the two groups as regard age.
Table (6): Comparison of IgE in group II chronic rhinosinusitis patients without nasal polyps (CRSwNP) IgE in group II.

\begin{tabular}{|c|c|c|}
\hline Patients No. & Local (U/ml) & Total $(\mathrm{U} / \mathrm{ml})$ \\
\hline 1 & 42 & 45 \\
\hline 2 & 40 & 35 \\
\hline 3 & 27 & 25 \\
\hline 4 & 22 & 18 \\
\hline 5 & 77 & 78 \\
\hline 6 & 68 & 82 \\
\hline 7 & 55 & 45 \\
\hline 8 & 45 & 43 \\
\hline 9 & 32 & 28 \\
\hline 10 & 27 & 28 \\
\hline 11 & 25 & 29 \\
\hline 12 & 32 & 23 \\
\hline 13 & 31 & 27 \\
\hline 14 & 72 & 75 \\
\hline 15 & 69 & 78 \\
\hline 16 & 68 & 74 \\
\hline 17 & 25 & 22 \\
\hline 18 & 23 & 19 \\
\hline 19 & 52 & 45 \\
\hline 20 & 42 & 39 \\
\hline 21 & 65 & 75 \\
\hline 22 & 79 & 89 \\
\hline 23 & 65 & 72 \\
\hline 24 & 62 & 72 \\
\hline 25 & 49 & 46 \\
\hline 26 & 37 & 46 \\
\hline 27 & 39 & 45 \\
\hline 28 & 68 & 78 \\
\hline 29 & 45 & 48 \\
\hline 30 & 37 & 42 \\
\hline Range & $22-79$ & $18-89$ \\
\hline Mean $\pm \mathrm{SD}$ & $47.33 \pm 17.9$ & $49 \pm 22.2$ \\
\hline \multirow[t]{2}{*}{ Paired $t$-test } & $t$ & 1.44 \\
\hline & $p$-value & 0.161 \\
\hline
\end{tabular}

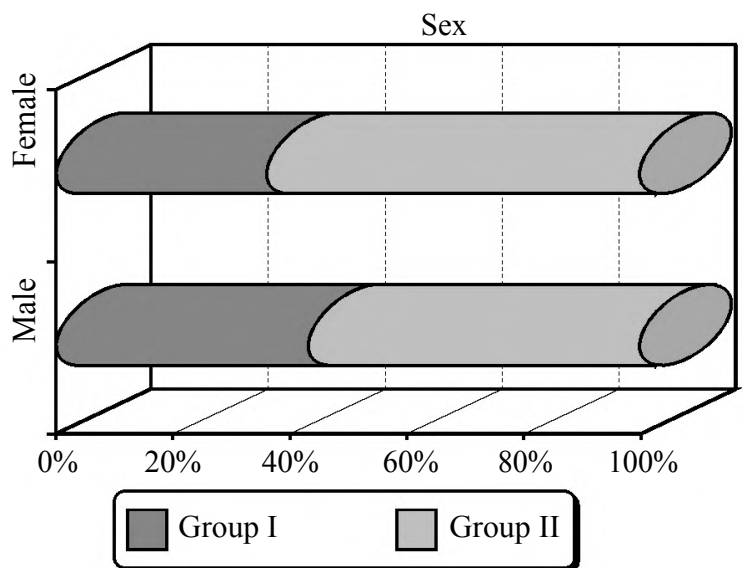

Fig. (2): Comparison between the two groups as regard sex. 


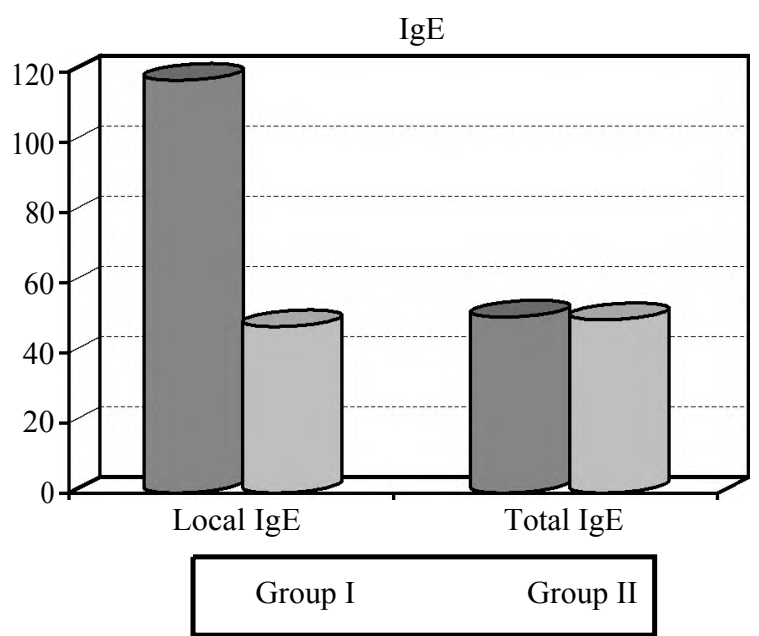

Fig. (3): Comparison of local and total IgE between two groups showing.

\section{Discussion}

Chronic rhinosinusitis constitutes one of the commonest conditions encountered in medicine and may present to a wide range of clinicians from primary care to accident and emergency, pulmonologists, allergists, otorhinolaryngologists and even intensivists and neurosurgeons when severe complications occur.

Allergy is caused by a continuous overproduction of IgE to environmental antigens. The accumulation of receptor-bound IgE molecules on exposure to specific allergen results in the production of inflammatory mediators (histamine, leukotriene and others) responsible for the allergic response [6].

Local production of $\operatorname{IgE}$ in the respiratory mucosa has been demonstrated in AR (allergen specific $\mathrm{IgE}$ ) and in CRSwNP (polyclonal IgE), suggesting a role for local $\mathrm{IgE}$ in the pathogenesis of these inflammatory diseases of the upper airway. It has been suggested that the majority of allergen-specific $\mathrm{IgE}$ in the peripheral blood is not derived from IgE-secreting cells in the blood but is produced locally in target organs of allergy such as the nasal mucosa. Considering the importance of local IgE production, it seems to be essential to develop noninvasive, reproducible and easy to perform approaches for measurement of local mucosal IgE production.

In this study Group I shows that the mean value for local $\mathrm{IgE}$ was 117.83 ranging from 46 to 178 with standard deviation 27.9. the mean value for total IgE was 50.2 ranging from 12 to 108 with standard deviation 28.39. This means statistically significant between total and local IgE in chronic rhinosinusitis patients with nasal polyps. Group II shows that the mean value for local IgE was 47.33 ranging from 22 to 79 with standard deviation 17.9. The mean value for total $\mathrm{IgE}$ was 49 ranging from 18 to 89 with standard deviation 22.2. This means statistically not significant between total and local IgE.

According to Watelet J., et al. [7], this study examined local IgE specific to S.aureus in CRSwNP patients compared to CRSsNP patients and found significantly higher levels in CRSwNP patients compared to CRSsNP patients.

In 2007, Paul Van Cauwenberge et al. [8], suggest that there is an association between increased levels of total IgE, local specific IgE, and eosinophilic inflammation in NPs, which may be of relevance in the pathophysiology of nasal polyposis. Samples were prepared from nasal tissue of 20 patients with NPs and 20 patients without NPs and analyzed for concentrations total and specific $\mathrm{IgE}$ for inhalant allergens allergens and Staphylococcus aureus enterotoxins were measured (ImmunoCAP). Results found the concentrations of total IgE higher in NP tissue compared with nonpolyp tissue.

In 2009, Matthias F. Kramer et al. [9], compared concentrations of Interleukin-5 (IL-5), immunoglobulin E (IgE), Eosinophilic Cationic Protein (ECP) in nasal secretion and serum of patients with chronic nonallergic sinusitis, allergic rhinitis, and nonallergic nasal polyposis. The study was on Nineteen patients with chronic nonallergic sinusitis, 24 patients with seasonal allergic rhinitis, and 18 patients with nonallergic nasal polyposis were included in the study. Eight healthy, nonallergic probands served as control subjects. Results were equally elevated concentrations of IL-5 and IgE in patients with allergic rhinitis and nonallergic nasal polyposis but not elevated in chronic nonallergic sinusitis.

In 2005, P. Gevaert G., et al. [10], showed that nasal tissue and serum were obtained from 12 control and 24 bilateral NP patients. Nasal culture from the middle meatus demonstrated staphylococcal colonization in 17/24 NP patients and in three of 12 controls $(p 0.02)$. The results demonstrate a significant increase in concentrations of $\operatorname{IgE}$, albumin, and eosinophil counts in nasal polyp tissue compared with control tissue. Total $\operatorname{IgE}$ and $\operatorname{IgE}$ antibody concentrations were in all cases higher in tissue compared with serum. The IgE/albumin ratios in polyp tissue and in serum were dissociated, 
indicating that tissue $\operatorname{IgE}$ is rather the result of a local IgE production than of extravasation.

According to Small P. et al. [11], this study showed that eighteen of 24 patients undergoing nasal polypectomies demonstrated polyp fluid IgE higher than corresponding serum values. Allergenspecific IgE was detected in polyp fluid of 19/24 patients. Since only 9/19 had positive skin tests, ten patients had specific IgE locally in polyp tissue which could not be detected systemically.

According to VanZele et al. [12], this study looked at the local IgE and eosinophilic immune response to S.aureus colonization by examining middle meatus tissue homogenates. Although they found increased S.aureus colonization of nasal polyps (64\%), this phenomenon was not found in CRSsNP (27\%) or controls (33\%). The prevalence of $\mathrm{IgE}$ antibodies to $\mathrm{S}$ aureus enterotoxins in the tissue paralleled colonization rates, suggesting that the local immune response to the bacteria may play a role in the formation of polyps but not in CRS sNP.

\section{Conclusion:}

Local IgE production plays an important role in pathogenesis of chronic rhinosinusitis with nasal polyps rather than chronic rhinosinusitis without nasal polyps.

\section{Limitations:}

Consistent with current knowledge of the pathophysiology of nasal polyposis, new therapeutic approaches could focus on the $\mathrm{T}$ cell as the orchestrating cell and IgE antibodies, as well as on tissue destruction and remodeling processes. Recently, the introduction of monoclonal humanized antibodies and IL-5 antagonists has opened new perspectives.

\section{Acknowledgments:}

NAD.

\section{Funding:}

The research was done in Tanta University Hospital with no other funding resources.

\section{Conflicts of interest:}

No conflicts of interest declared.
Authors' contributions:

All authors had equal role in design, work, statistical analysis and manuscript writing.

\section{References}

1- BOUSQUET J., BACHERT C., CANONICA G.W., CASALE T.B., CRUZ A.A. and LOCKEY R.J.: Unmet needs in severe chronic upper airway disease (SCUAD). The Journal of allergy and clinical immunology, Sep., 124 (3): 428-33, 2009.

2- FOKKENS W.J., LUND V.J., MULLOL J., BACHERT C., ALOBID I. and BAROODY F.: European position paper on rhinosinusitis and nasal polyps 2012. Rhinology, Apr., 12; 50: 1-298, 2012.

3- BOUSQUET J., KHALTAEV N., CRUZ A.A., DENBURG J., FOKKENS W.J. and TOGIAS A.: Allergic Rhinitis and its Impact on Asthma (ARIA) 2008 update (in collaboration with the World Health Organization, GA (2) LEN and AllerGen). Allergy, p. 8-160, 2008.

4- BLOMME K., TOMASSEN P., LAPEERE H., HUVENNE W., BONNY M. and ACKE F.: Prevalence of Allergic Sensitization versus Allergic Rhinitis Symptoms in an Unselected Population. Int. Arch. Allergy Immunol., 160 (2): 200-7, 2013.

5- FOKKENS W.J.: Thoughts on the pathophysiology of nonallergic rhinitis. Curr. Allergy Asthma Rep., May, 2 (3): 203-9, 2002.

6- CASALE T.B., CONDEMI J., LaFORCE C., NAYAK A., ROWE M. and WATROUS M.: Effect of omalizumab on symptoms of seasonal allergic rhinitis: A randomized controlled trial. Jama. American Medical Association; Dec. 10, 286 (23): 2956-67, 2001.

7- WATELET J.B. and ELOY P.H.: Drug management in chronic rhinosinusitis: Identification of the needs Ther. Clin. Risk Manag Mar., 3 (1): 47-57, 2007.

8- VAN CAUWENBERGE P. and BACHERT C.: Clin. Exp. Allergy, Dec., 37 (12): 1840-7. Epub. 2007 Oct. 17, 2007.

9- KRAMER M.F. and RASP G.: Nasal polyposis: Eosinophils and interleukin-5. Allergy, 54: 669-80, 1999.

10- BACHERT C. and HOLTAPPELS G.: An update on the impact of Staphylococcus aureus enterotoxins in chronic sinusitis with nasal polyposis. Rhinology, Sep., 43 (3): 162-8, 2005.

11- SMALL P., BARRETT D., FRENKIEL S., ROCHON L., COHEN C. and BLACK M.: Local specific IgE production in nasal polyps associated with negative skin tests and serum RAST Annals of Allergy [01 Nov., 55 (5): 736-9], 1985.

12- VAN ZELE T., GAEVERT P. and WATELET J.: Staphylococcus aureus colonization and IgE antibody formation to enterotoxins is increased in nasal polyposis. J. Allergy Clin. Immunol., 114: 981-3, 2004. 


\section{دراسة مقارنة للغلوبيولين (ه) في الآغشية الهخاطية للآنف والدم

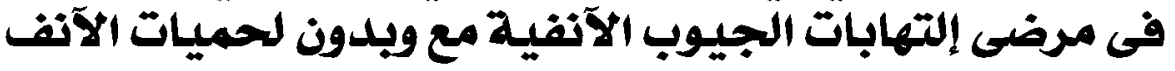

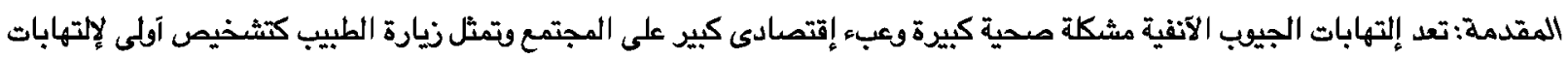

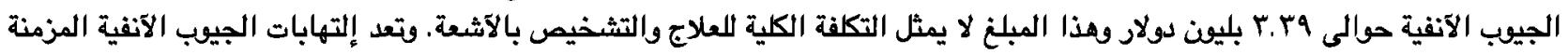

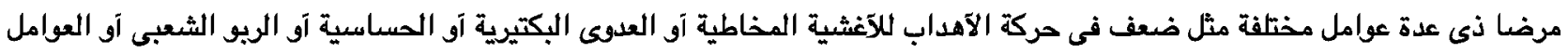

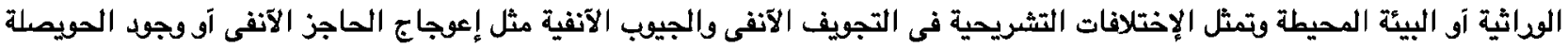

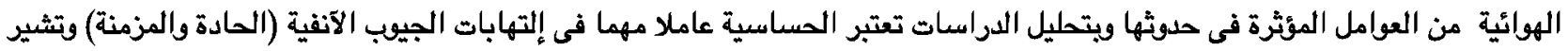

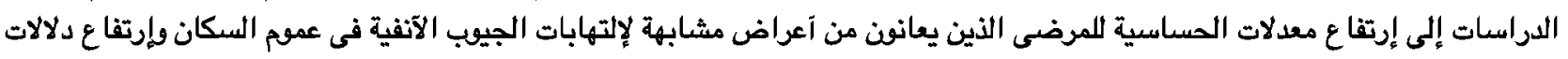
الحساسية فى مرضى إلتهابات الجيوب الآنفية.

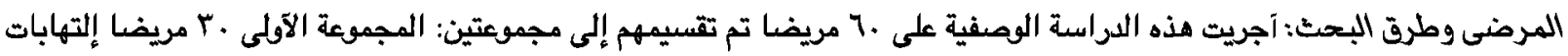

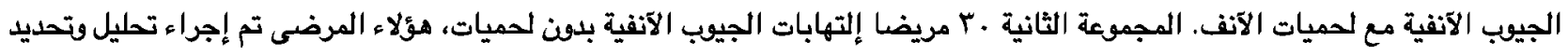

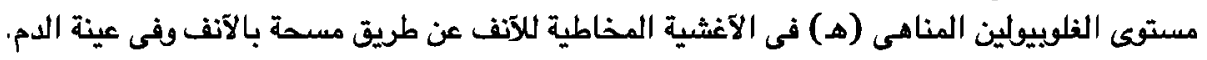
نتائج البحث: وكانت نتايج نسبة الفلوبيولين المناعى (هـ) كالآتى:

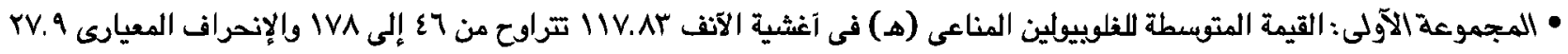

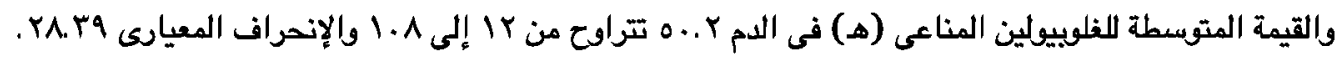

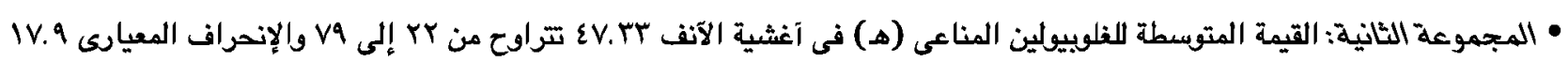

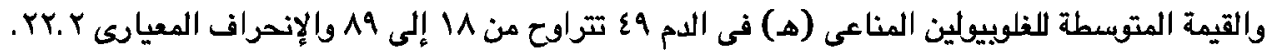

الإستتاج: تعتبر الحساسية عاملا مؤثرا في إلتهابات الجيوب الآنفية مع لحميات الآنف آكثر من إلتهابات الجيوب الآنفية بدفن لحميات 